
and Aromatic Plants

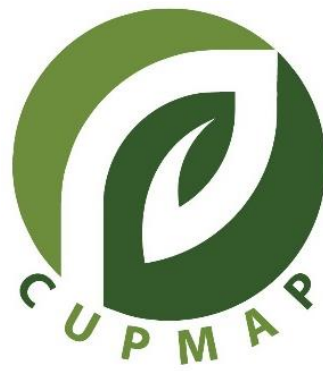

\title{
Effects of Tribulus terrestris, Avena sativa and White Ginseng on Adiponectin, Leptin, Resistin, Fatty Acid Binding Protein 4, Homocysteine and Paraoxonase-1 Levels in Hypercholesterolemic Rats
}

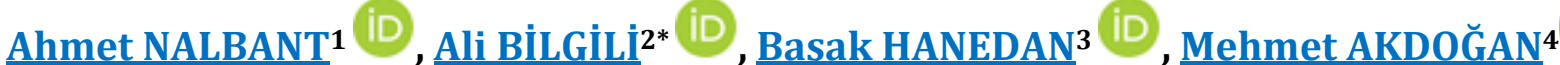 \\ 1Department of Internal Medicine, Faculty of Medicine, University of Sakarya, 54050, Sakarya, TURKEY \\ ${ }^{2}$ Department of Pharmacology and Toxicology, Faculty of Veterinary Medicine, University of Ankara, \\ 06110, Ankara, TURKEY \\ *Corresponding author: abilgili@gmail.com \\ ${ }^{3}$ Department of Internal Medicine, Faculty of Veterinary Medicine, University of Ataturk, \\ 25240, Erzurum, TURKEY \\ ${ }^{4}$ Department of Medical Biochemistry, Faculty of Medicine, University of Sakarya, TR-54050, Sakarya, TURKEY
}

\section{Abstract}

This study was aimed to evaluate the effects of Tribulus terrestris (TT), Avena sativa (AS), white ginseng (WG), and a triple combination (TC) powder on adipokines, homocysteine and paraoxonase-1 levels in hypercholesterolemic rats. Hypercholesterolemia in rats was induced by diet added $2 \%$ cholesterol. Herbal treatment groups consisted of Group III (TT), Group IV (AS), Group V (WG) and Group VI (triple combination of TT, AS and WG). Significant increase in total cholesterol, LDL-C, homocysteine, leptin and resistin levels $(\mathrm{P}<0.05)$ and insignificant decrease in adiponectin, and paraoxonase-1 levels $(\mathrm{P}>0.05)$ were found in hypercholesterolemic rats. The treatment combination with TT, AS and WG significantly reduced total cholesterol, LDL-C, homocysteine, leptin and resistin levels in hypercholesterolemic rats $(\mathrm{P}<0.05)$. In conclusion, it was found that TT, AS and WG had positive effects on reversing the effects of hypercholesterolemia in rats. The combination treatment with TT, AS and WG may have therapeutic effects in the treatment of hypercholesterolemia.

Key Words: Hypercholesterolemia, Adipokines, Homocysteine, Paraoxonase-1, Herbal treatment

\section{Introduction}

Obesity incidence is appeared to increase during recent decades. It may be accompanied with adipose tissue dysfunction, fatty liver disease, dyslipidemia, and atherosclerosis (Bluher, 2009). Hypercholesterolemia causes adipocyte hypertrophy, and the inflammation and endocrine dysfunction of adipose tissue (Aguilar and Fernandez, 2014). Adipokines are secreted by adipose tissue (Cobbold, 2019). Some adipokines are adiponectin, leptin, resistin and fatty acid binding protein 4 (FABP4) (Tu et al., 2017; Li and Shen, 2019).

Adiponectin enhances that skeletal muscles utilize glucose and fatty acids and is linked with lipoprotein metabolism (Yanai and Yoshida, 2019). Leptin has a role on 
suppression of appetite, enhancing of energy expended, and regulation of body weights (Mechanick et al., 2018). Resistin levels are increased in obesity induced by diet (Zieba et al., 2020). It has been also determined that resistin levels are increased in obese women (Alissa et al., 2019). FABP4 is highly expressed in adipocytes and macrophages (Lamounier-Zepter et al., 2013), and involved in the coordination of lipid transportation in the cellular level (Tu et al., 2017).

Hyperhomocysteinemia causes increase of hydrogen peroxide production, endothelial dysfunction and increase of oxidation of lowdensity lipoproteins (Jamwal and Sharma, 2018). Serum paraoxonase-1 (PON1) has the protective effects against atherogenesis by contributing to the antioxidant properties of high density lipoprotein (Shekhanawar et al., 2013). In addition, PON-1 acts on suppressing the inflammatory response of macrophages, and attenuating plaque progression (Aharoni et al., 2013).

Chronic diseases caused by hypercholesterolemia lead to an important rate of deaths in the developed countries (Gouveia et al., 2004). Pharmacological agents for the treatment of hypercholesterolemia include cholesterol synthesis inhibition, reduction of fat absorption in the gastrointestinal system, and degradation of fatty acids. These agents may present side effects, therapeutic insufficiency, and reduced tolerability (Klein-Szanto and Bassi, 2019). For example, statins are used for lowering serum lipid levels in hypercholesterolemic patients. However, statins have adverse effects such as decrease of insulin sensitivity and adiponectin levels (Koh et al., 2008; Koh et al., 2010; Koh et al., 2016), and liver toxicity (Abd El Aal et al., 2017). Thus, new plantderived treatment choices are explored for lowering blood lipid levels.
Tribulus terrestris (TT) has been used as a traditional medicine for a long time by virtue of chemical constituents that it contains flavonoids, flavonol glycosides and alkaloids. It has beneficial activities including hypolipidemic, antidiabetic, cardiotonic, hepatoprotective and anti-inflammatory (Chhatre et al., 2014).

Avena sativa (AS) is used for food and traditional medicine. It has various pharmacological activities such as cholesterol lowering effect, antioxidant activity, anti-atherogenic activity, and lowering the obesity risk (Singh et al., 2013). Ginseng is used for centuries for treating diseases (Davis and Behm, 2019). Ginseng has therapeutic effects on cardiovascular diseases (Xu et al., 2018), immune function (Kim et al., 2018), obesity (Lee et al., 2013a), hyperlipidemia, and hyperglycemia (Chung et al., 2016) via bioactive compounds (Liu et al., 2018).

The treatment of hypercholesterolemia with herbal medicines is extensively evaluated. However, there is need to know the effects of herbal medicines on adipokines in the treatment of hypercholesterolemia. Thus, in this study, the effects of TT, AS, white ginseng (WG), and a triple combination (TC) powder were evaluated on adipokines, homocysteine and PON-1 levels in hypercholesterolemic rats.

\section{Material and Methods}

2.1. Animals and Materials: The present study material consisted of 42 Wistar albino rats, 2.5 months old. The rats were kept in a standard condition (12 h light/dark; temperature: $25^{\circ} \mathrm{C}$ ). All rats were acclimated before experiment. The approval of Kobay's Local Ethics Committee was obtained for this experimental study. The study consisted of six groups. The rats of group I were fed with pellet feed. Other groups were fed with $2 \%$ added cholesterol (Sigma Aldrich C- 
75209). 15\% TT (milled seed); 7.5\% AS (seed); 5\% WG (root); and 7.5 TT\%, 3.75\% AS, 2.5\% WG were added to the diet of Group III, IV, V, VI, respectively. Upon completion of the study period, the rats were administered with xylazine $(10 \mathrm{mg} / \mathrm{kg})$ and ketamine $(90 \mathrm{mg} / \mathrm{kg})$. Centrifugation of blood samples and freezing serum samples were made.

\subsection{Assessment of Sera Biochemical}

Parameters: The levels of sera total cholesterol, LDL-C, HDL-C, and triglyceride were measured using a COBAS-C501 chemistry analyzer (Roche Diagnostics GmbH, D-68298 Mannheim, Germany). Rat homocysteine levels by the quantitative sandwich enzyme immunoassay technique (Rat homocysteine Cusabio ELISA Kit), PON1 activities by a novel automated photometric method developed by Erel (Aslan et al., 2007), adiponectin levels by the quantitative sandwich enzyme immunoassay technique (Rat adiponectin, ADP ELISA Kit), plasma leptin levels by the sandwich enzyme-linked immunosorbent method (Rat Leptin BioVendor), resistin levels by ELISA (Rat Resistin BioVendor) and FABP4 levels by ELISA technique (Rat fatty acid binding protein, BioVendor ELISA kit) were measured.

\subsection{Statistical Analysis: Whether} parameters were normally distributed was analyzed by Shapiro-Wilk test. KruskalWallis test and one-way ANOVA was used for non-normally distributed parameters and normally distributed parameters, respectively. Pearson correlation for the correlation analyses of all parameters was used. $\mathrm{P}<0.05$ was significant.

\section{Results and Discussion}

The total cholesterol, HDL-C, LDL-C, triglyceride, homocysteine, PON-1, adiponectin, FABP4, leptin and resistin results are given in Table 1 . There was significant increase of total cholesterol and LDL-C levels, and significant decrease of HDL-C levels in group II than group I $(\mathrm{P}<0.05)$. The rats of group VI had significant decreased total cholesterol and LDL-C levels than group I $(\mathrm{P}<0.05)$.

There was a significant increased homocysteine levels in group II than group I $(\mathrm{P}<0.05)$. The treatment of combination of TT, AS, and WG in Group VI significantly decreased homocysteine levels than group II of hypercholesterolemic rats $(\mathrm{P}<0.05)$. It was determined that PON-1 activities were insignificantly decreased in hypercholesterolemic rats and the treatment with TT, AS, and WG and TC insignificantly increased PON-1 activities in hypercholesterolemic rats $(\mathrm{P}>0.05)$. In hypercholesterolemic rats, adiponectin levels were non-significantly decreased. Herbal treatment insignificantly increased adiponectin levels in hypercholesterolemic rats $(\mathrm{P}>0.05)$. FABP4 levels were not significantly changed in the treatment groups $(\mathrm{P}>0.05)$. There was significant increase of leptin and resistin levels in group II than group I, but significant decrease of leptin and resistin levels in group VI than group II $(\mathrm{P}<0.05)$.

Significant correlation analyses for all measured parameters performed using Pearson correlation were given in Table 2 . There was a correlation of total cholesterol with triglyceride, HDL-C, LDL-C, homocysteine, adiponectin, and leptin; of homocysteine with total cholesterol, triglyceride, HDL-C, LDL-C, PON-1, adiponectin, leptin and resistin; of PON-1 with homocysteine, and leptin; of adiponectin with total cholesterol, HDL-C, and homocysteine; of leptin with total cholesterol, triglyceride, HDL-C, LDL-C, homocysteine, PON-1, and resistin; and of resistin with homocysteine and leptin. 
Table 1: The effects of TT, AS, WG and TC on adipokines, homocysteine and paraoxonase levels in hypercholesterolemic rats

\begin{tabular}{|c|c|c|c|c|c|c|}
\hline \multirow{2}{*}{ Parameters } & Group I & Group II & Group III & Group IV & Group V & Group VI \\
\cline { 2 - 7 } & Control & 2\% Chol & 2\% Chol + TT & 2\% Chol + AS & 2\% Chol + WG & 2\% Chol + TC \\
\hline $\begin{array}{c}\text { Total } \\
\text { cholesterol } \\
\text { (mg/dl) }\end{array}$ & $69(55-84)$ & $91(85-108)^{\mathrm{a}}$ & $73(67-110)$ & $72(68-80)$ & $67(56-88)^{\mathrm{b}}$ & $70(56-73)^{\mathrm{c}}$ \\
\hline $\begin{array}{c}\text { Triglyceride } \\
\text { (mg/dl) }\end{array}$ & $55.86 \pm 4.62$ & $63.57 \pm 7.55$ & $52 \pm 4.20$ & $51.71 \pm 3.13$ & $49.29 \pm 6.19$ & $48.57 \pm 2.19$ \\
\hline $\begin{array}{c}\text { HDL-C } \\
\text { (mg/dl) }\end{array}$ & $41.00 \pm 2.25$ & $30.86 \pm 1.37^{\mathrm{d}}$ & $34.14 \pm 3.01$ & $36.57 \pm 1.41$ & $37.14 \pm 1.18$ & $37.86 \pm 0.50$ \\
\hline LDL-C (mg/dl) & $33.00 \pm 1.27$ & $39.43 \pm 0.68^{\mathrm{e}}$ & $36.29 \pm 1.24$ & $35.14 \pm 1.16$ & $35.00 \pm 1.27$ & $32.14 \pm 0.96^{\mathrm{f}}$ \\
\hline Homocysteine & $9.7(8.7-11.9)$ & $13.7(12.4-15.8)^{\mathrm{g}}$ & $10.9(9.7-15.3)$ & $11.6(11.2-13.7)^{\mathrm{h}}$ & $9.8(9.2-14.8)$ & $9.0(8.5-10.7)^{\mathrm{j}}$ \\
\hline Paraoxonase & $242.86 \pm 19.10$ & $190.86 \pm 4.94$ & $208.43 \pm 11.13$ & $215.57 \pm 11.25$ & $217.43 \pm 5.76$ & $239.57 \pm 14.59$ \\
\hline Adiponectin & $4.38(2.59-5.22)$ & $3.16(2.58-3.85)$ & $3.06(2.39-4.13)$ & $3.28(2.94-3.51)$ & $3.25(3.05-4.37)$ & $3.65(2.87-3.88)$ \\
\hline FAB4 & $2.70(1.60-7.60)$ & $3.10(0.89-5.20)$ & $3.70(0.39-6.40)$ & $3.50(2.80-5.70)$ & $2.90(1.39-5.90)$ & $2.40(1.39-5.70)$ \\
\hline Leptin & $2.18(1.87-2.51)$ & $4.54(4.13-5.42)^{\mathrm{k}}$ & $2.64(2.15-5.07)$ & $3.10(2.63-3.90)^{\mathrm{l}}$ & $2.93(1.96-3.14)$ & $2.59(2.31-2.93)^{\mathrm{m}}$ \\
\hline Resistin & $20.57 \pm 2.03$ & $28.70 \pm 2.0^{\mathrm{h}}$ & $25.48 \pm 0.73$ & $24.77 \pm 1.79$ & $22.30 \pm 1.57$ & $18.95 \pm 2.07^{\mathrm{c}}$ \\
\hline
\end{tabular}

Notes: Group I: Control group; Group II: Cholesterol treatment group; Group III: 2\% Cholesterol + TT treatment group; Group IV: $2 \%$ Cholesterol + AS treatment group; Group V: 2\% Cholesterol + WG treatment group; Group VI: 2\% Cholesterol + TC treatment group.

Each group consisted of 7 rats. All values were presented as mean \pm SEM or median (minimum - maximum).

${ }^{a} \mathrm{P}<0.05$ versus Group I; ${ }^{\mathrm{P}} \mathrm{P}<0.05$ versus Group II; $\mathrm{c} \mathrm{P}<0.05$ versus Group II; $\mathrm{d}<0.05$ versus Group I; $\mathrm{e} P<0.05$ versus Group I; ${ }^{\mathrm{P}}<0.05$ versus Group II; : $\mathrm{P}<0.05$ versus Group I; ${ }^{\mathrm{hP}}<0.05$ versus Group VI; ${ }^{\mathrm{P}}<0.05$ versus Group II; ${ }^{\mathrm{kP}}<0.05$ versus Group I; $\mathrm{P}<0.05$ versus Group I; ${ }^{\mathrm{mP}}<0.05$ versus Group II; $\mathrm{n}^{\mathrm{P}}<0.05$ versus Group I; $\mathrm{P}<0.05$ versus Group II.

Table 2: Correlations among cholesterol, adipokines, homocysteine and paraoxonase levels in hypercholesterolemic rats

\begin{tabular}{|c|c|c|c|c|c|c|c|c|c|}
\hline $\begin{array}{c}\text { Pearson } \\
\text { correlation levels } \\
\text { and } P \text { values }\end{array}$ & 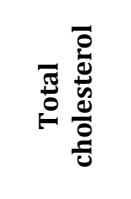 & 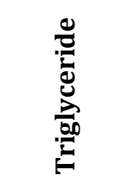 & 产 & ب্د & 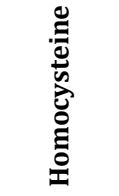 & 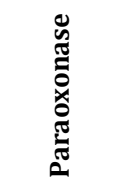 & 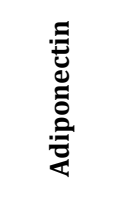 & 紊 & 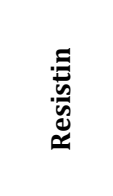 \\
\hline Total cholesterol & & $\begin{array}{l}\mathrm{r}=0.542 \\
\mathrm{P}=0.000\end{array}$ & $\begin{array}{l}r=-0.494 \\
P=0.001\end{array}$ & $\begin{array}{l}r=0.625 \\
P=0.000\end{array}$ & $\begin{array}{l}r=0.735 \\
P=0.000\end{array}$ & & $\begin{array}{l}r=-0.346 \\
P=0.025\end{array}$ & $\begin{array}{c}r=0.393 \\
P=0.01\end{array}$ & \\
\hline Triglyceride & $\begin{array}{l}\mathrm{r}=0.542 \\
\mathrm{P}=0.000\end{array}$ & & $\begin{array}{l}\mathrm{r}=-0.361 \\
\mathrm{P}=0.019\end{array}$ & $\begin{array}{l}\mathrm{r}=0.442 \\
\mathrm{P}=0.003\end{array}$ & $\begin{array}{l}\mathrm{r}=0.468 \\
\mathrm{P}=0.002\end{array}$ & & & $\begin{array}{l}\mathrm{r}=0.309 \\
\mathrm{P}=0.047\end{array}$ & \\
\hline HDL-C & $\begin{array}{l}\mathrm{r}=-0.494 \\
\mathrm{P}=0.001\end{array}$ & $\begin{array}{c}r=-0.361 \\
P=0.19\end{array}$ & & $\begin{array}{l}r=-0.606 \\
P=0.000\end{array}$ & $\begin{array}{l}r=-0.531 \\
P=0.000\end{array}$ & & $\begin{array}{c}r=0.358 \\
P=0.02\end{array}$ & $\begin{array}{l}r=-0.419 \\
P=0.006\end{array}$ & \\
\hline LDL-C & $\begin{array}{l}\mathrm{r}=0.625 \\
\mathrm{P}=0.000\end{array}$ & $\begin{array}{l}\mathrm{r}=0.442 \\
\mathrm{P}=0.003\end{array}$ & $\begin{array}{l}r=-0.606 \\
P=0.000\end{array}$ & & $\begin{array}{l}\mathrm{r}=0.493 \\
\mathrm{P}=0.001\end{array}$ & & & $\begin{array}{l}\mathrm{r}=0.536 \\
\mathrm{P}=0.000\end{array}$ & \\
\hline Homocysteine & $\begin{array}{l}r=0.735 \\
P=0.000\end{array}$ & $\begin{array}{l}r=0.468 \\
P=0.002\end{array}$ & $\begin{array}{l}r=-0.531 \\
P=0.000\end{array}$ & $\begin{array}{l}r=0.493 \\
P=0.001\end{array}$ & & $\begin{array}{l}r=-0.430 \\
P=0.004\end{array}$ & $\begin{array}{c}r=-0.352 \\
P=0.02\end{array}$ & $\begin{array}{l}r=0.531 \\
P=0.000\end{array}$ & $\begin{array}{l}r=0.491 \\
P=0.001\end{array}$ \\
\hline Paraoxonase & & & & & $\begin{array}{l}r=-0.430 \\
P=0.004\end{array}$ & & & $\begin{array}{l}r=-0.406 \\
P=0.008\end{array}$ & \\
\hline Adiponectin & $\begin{array}{c}\mathrm{r}=-0.346 \\
\mathrm{P}=0.02\end{array}$ & & $\begin{array}{c}\mathrm{r}=0.358 \\
\mathrm{P}=0.02\end{array}$ & & $\begin{array}{c}\mathrm{r}=-0.352 \\
\mathrm{P}=0.02\end{array}$ & & & & \\
\hline Leptin & $\begin{array}{c}r=0.393 \\
P=0.01\end{array}$ & $\begin{array}{l}\mathrm{r}=0.309 \\
\mathrm{P}=0.047\end{array}$ & $\begin{array}{l}r=-0.419 \\
P=0.006\end{array}$ & $\begin{array}{l}r=0.536 \\
P=0.000\end{array}$ & $\begin{array}{l}r=0.531 \\
P=0.000\end{array}$ & $\begin{array}{l}r=-0.406 \\
P=0.008\end{array}$ & & & $\begin{array}{l}\mathrm{r}=0.491 \\
\mathrm{P}=0.001\end{array}$ \\
\hline Resistin & & & & & $\begin{array}{l}\mathrm{r}=0.491 \\
\mathrm{P}=0.001\end{array}$ & & & $\begin{array}{l}\mathrm{r}=0.491 \\
\mathrm{P}=0.001\end{array}$ & \\
\hline
\end{tabular}

Notes: r: Pearson correlation; HDL-C: High density lipoprotein cholesterol; LDL-C: Low density lipoprotein cholesterol.

In this study, there were significant decreases of HDL-C, significant increase of total cholesterol and LDL-C levels and insignificant decrease of adiponectin levels in hypercholesterolemic rats. It was found that there was an inverse relation between high total cholesterol levels and low adiponectin levels and a positive correlation between HDL-C and adiponectin levels in hypercholesterolemic rats. Moreover, in this 
study, hypercholesterolemia caused significant increase in homocysteine, leptin, and resistin levels, and insignificant decrease in adiponectin and PON-1 levels in rats. Increased resistin levels in hypercholesterolemic rats might be explained with promoting inflammation and disease conditions such as metabolic syndrome and causing the antagonistic activity on the protective adiponectin (Acquarone et al., 2019). High leptin levels in hypercholesterolemic rats might be associated with stimulating the production of proinflammatory cytokine (Berger and Polotsky, 2018). High homocysteine and low adiponectin levels might be attributed to tend possible inflammation and atherosclerosis (Lee et al., 2013b). In this study, homocysteine was found to be correlated with total cholesterol, triglyceride, HDL-C, LDL-C, PON-1, adiponectin, leptin, and resistin.

The treatment of TC in group VI provided beneficial effects by significantly decreasing homocysteine, leptin and resistin levels, and insignificantly increasing adiponectin levels in hypercholesterolemic rats. Beneficial effects by herbal treatments have been showed in hypercholesterolemic rats. For example, Abd El Aal et al. (2017) have demonstrated that carvacrol significantly decreases total cholesterol, triglycerides, LDL, leptin, and increases HDL and adiponectin. Metwally et al. (2019) have reported that reduction of visceral adiposity and serum leptin and resistin levels, increase in serum adiponectin levels, and reduction in serum total cholesterol, triglyceride, insulin and glucose levels are determined in $\mathrm{M}$. alba leaf extract treated hypercholesterolemic rats for 8 weeks. Resveratrol has an increasing activity of adiponectin and decreasing activity of leptin and insulin in hypercholesterolemic rabbits and has a therapeutic potential for lipidlowering effect (Jimoh et al., 2018).
Tribulus terrestris (1000 mg/d) decreased total cholesterol and LDL levels in women with type 2 diabetes (Samani et al., 2016). TT is reported to improve adiponectin levels but not significant in diabetic rats (Gandhi et al., 2013), and to decrease serum leptin and homocysteine levels in hypertensive rats (Jiang et al., 2017). In this study, TT in the diet of hypercholesterolemic rats insignificantly decreased LDL-C, homocysteine, leptin and resistin levels and insignificantly increased HDL-C, and PON-1 levels. This can be attributed to beneficial effects on its hypolipidemic activity.

Ginsenoside Rg1 of ginseng decreased lipid accumulation in obese mice (Liu et al., 2018). Fermented ginseng had improvement effect on hypercholesterolemia, and reduction effects in FABP4 expression, IL-1 $\beta$ and IL-6 expressions of adipose tissue (Li et al., 2018). Furthermore, it has been showed that black ginseng $(200 \mathrm{mg} / \mathrm{kg})$ decreases total serum cholesterol and LDL-C levels, and attenuates the lipogenesis genes in hypercholesterolemic rats (Saba et al., 2016). Chung et al. (2016) have reported that plasma adiponectin levels are increased and leptin and resistin levels are decreased with treatment of red ginseng in mice exposed to high fat diet. In addition, ginsenoside $\mathrm{R} 1$ treatment has been reported to improve central leptin sensitivity in obese mice (Wu et al., 2018). In this study, WG in the diet of hypercholesterolemic rats insignificantly decreased LDL-C, homocysteine, leptin and resistin levels and insignificantly increased HDL-C, and PON-1 levels. It is determined that white ginseng has positive effects on improvement of adipokines secreted by adipose tissue and improvement of homocysteine and PON-1 levels in rats. Oat protein and oat glucan can decrease plasma LDL-C levels by increasing of fecal total lipids in hypercholesterolemic hamsters (Tong et al., 2016). Furthermore, boiled oatmeal than brewed oatmeal has been reported to be more efficient on 
lowering plasma and liver lipid levels in hypercholesterolemic rats (Ban et al., 2015). Oat $\beta$-glucan is reported to significantly decrease LDL-C and apoB in humans and to be a possible strategy on cardiovascular disease reduction (Ho et al., 2016). Similarly, oat beta glucan of $\geq 3 \mathrm{~g}$ added diet provided LDL cholesterol reduction (Whitehead et al., $2014)$. Oat- $\beta$ glucan is reported to attenuate the intestinal FABP mRNA in rats (Drozdowski et al., 2010). However, in this study, no significant changes for FABP4 among groups were found.

Oat fiber decrease weight of body adipose tissues, increase serum adiponectin levels, increase protein expressions related to the lipolysis in mice fed a high-fat diet (Han et al., 2017), decrease serum lipids and leptin levels in mice fed a high-fat/cholesterol diet (Zhang et al., 2016). Oat beta glucan had no effects on changes of homocysteine levels and had a reduction effect on total cholesterol and LDL-C levels in hypercholesterolemic adults (Queenan et al., 2007). In this study, AS in the diet of hypercholesterolemic rats insignificantly decreased LDL-C, homocysteine, leptin, and resistin levels and insignificantly increased HDL-C, and PON-1 levels.

\section{Conclusion}

It was determined that TT, AS and WG had positive effects on reversing the effects of hypercholesterolemia in rats. In addition, the treatment of combination of TT, AS and WG was determined to have therapeutic potential in the treatment of hypercholesterolemia by significantly decreasing homocysteine, leptin and resistin levels, and insignificantly increasing adiponectin and PON-1 levels in hypercholesterolemic rats.

\section{Acknowledgements}

\section{Conflict of interest}

There is no any conflicts of interest in the course of conducting the research among authors.

\section{References}

1. Abd El Aal, H.A., Ahmed, L.A., Hassan, W.A., Fawzy, H.M., and Moawad H., 2017. Combination of carvacrol with simvastatin improves the lipidlowering efficacy and alleviates simvastatin side effects. Journal of Biochemical and Molecular Toxicology, 31, e21981. DOI number: 10.1002/jbt.21981.

2. Acquarone, E., Monacelli, F., Borghi, R., Nencioni, A., and Odetti, P., 2019. Resistin: A reappraisal. Mechanisms of Ageing and Development, 178, 4663. DOI number: 10.1016/j.mad.2019.01.004.

3. Aguilar, D., and Fernandez, M.L., 2014. Hypercholesterolemia induces adipose dysfunction in conditions of obesity and nonobesity. Advances in Nutrition, 5 (5), 497-502.

4. Aharoni, S., Aviram, M., and Fuhrman, B., 2013. Paraoxonase 1 (PON1) reduces macrophage inflammatory responses. Atherosclerosis, 228 (2), 353-361. DOI number: 10.1016/j.atherosclerosis.2013.03.005.

5. Alissa, E.M., Alzughaibi, L.S., and Marzouki, Z.M., 2019. Association between serum resistin, adiposity measures and inflammatory makers in women without cardiovascular diseases. Chemistry and Physics of Lipids, 218, 136-140. DOI number: 10.1016/j.chemphyslip.2018.12.005.

6. Aslan, M., Kosecik, M., Horoz, M., Selek, S., Celik, H., and Erel, O., 2007. Assessment of paraoxonase and arylesterase activities in patients with iron deficiency anemia. Atherosclerosis, 191 (2), 397-402. DOI number: 10.1016/j.atherosclerosis.2006.04.007.

7. Ban, Y., Qiu, J., Ren, C., and Li, Z., 2015. Effects of different cooking methods of oatmeal on preventing the diet-induced increase of cholesterol level in hypercholesterolemic rats. Lipids in Health and Disease, 14, 135. DOI number: 10.1186/s12944-0150138-7.

8. Berger, S., and Polotsky, V.Y., 2018. Leptin and leptin resistance in the pathogenesis of obstructive sleep apnea: A possible link to oxidative stress and cardiovascular complications. Oxidative Medicine and Cellular Longevity, 2018, 5137947. DOI number: 10.1155/2018/5137947.

9. Bluher, M., 2009. Adipose tissue dysfunction in obesity. Experimental and Clinical Endocrinology and Diabetes, 117 (6), 241-250. DOI number: 10.1055/s-0029-1192044.

10. Chhatre, S., Nesari, T., Somani, G., Kanchan, D., and Sathaye, S., 2014. Phytopharmacological overview of 
Tribulus terrestris. Pharmacognosy Reviews, 8 (15), 45-51. DOI number: 10.4103/0973-7847.125530.

11. Chung, S.I., Nam, S.J., Xu, M., Kang, M.Y., and Lee, S.C., 2016. Aged ginseng (Panax ginseng Meyer) reduces blood glucose levels and improves lipid metabolism in high fat diet-fed mice. Food Science and Biotechnology, 25 (1), 267-273. DOI number: 10.1007/s10068-016-0039-1.

12. Cobbold, C., 2019. Type 2 diabetes mellitus risk and exercise: is resistin involved? The Journal of Sports Medicine and Physical Fitness, 59 (2), 290-297. DOI number: 10.23736/s0022-4707.18.08258-0.

13. Davis, M.P., and Behm, B., 2019. Ginseng: A Qualitative review of benefits for palliative clinicians. The American Journal of Hospice and Palliative Care, 36 (7), 630-659. DOI number: 10.1177/1049909118822704.

14. Drozdowski, L.A., Reimer, R.A., Temelli, F., Bell, R.C., Vasanthan, T., and Thomson, A.B., 2010. Betaglucan extracts inhibit the in vitro intestinal uptake of long-chain fatty acids and cholesterol and downregulate genes involved in lipogenesis and lipid transport in rats. The Journal of Nutritional Biochemistry, 21 (8), 695-701. DOI number: 10.1016/j.jnutbio.2009.04.003.

15. Gandhi, S., Srinivasan, B.P., and Akarte, A.S., 2013. Potential nephrotoxic effects produced by steroidal saponins from hydro alcoholic extract of Tribulus terrestris in STZ-induced diabetic rats. Toxicology Mechanisms and Methods, 23 (7), 548-557. DOI number: 10.3109/15376516.2013.797533.

16. Gouveia, M., Borges, M., Costa, J., and Carneiro, A.V., 2004. Burden of disease from hypercholesterolemia in Portugal. Revista Portuguesa de Cardiologia, 23 (2), 255-270.

17. Han, S.F., Jiao, J., Zhang, W., Xu, J.Y., Zhang, W., Fu, C.L., and Qin, L.Q., 2017. Lipolysis and thermogenesis in adipose tissues as new potential mechanisms for metabolic benefits of dietary fiber. Nutrition, 33, 118-124. DOI number: 10.1016/j.nut.2016.05.006.

18. Ho, H.V., Sievenpiper, J.L., Zurbau, A., Blanco Mejia, S., Jovanovski, E., Au-Yeung, F., Jenkins, A.L., and Vuksan, V., 2016. The effect of oat betaglucan on LDL-cholesterol, non-HDL-cholesterol and apoB for CVD risk reduction: a systematic review and meta-analysis of randomised-controlled trials. The British Journal of Nutrition, 116 (8), 13691382. DOI number: $10.1017 / \mathrm{s} 000711451600341 \mathrm{x}$.

19. Jamwal, S., and Sharma, S., 2018. Vascular endothelium dysfunction: a conservative target in metabolic disorders. Inflammation Research, 67, 391405. DOI number: 10.1007/s00011-018-1129-8.

20. Jiang, Y.H., Guo, J.H., Wu, S., and Yang, C.H., 2017. Vascular protective effects of aqueous extracts of Tribulus terrestris on hypertensive endothelial injury. Chinese Journal of Natural Medicines, 15 (8), 606-614. DOI number: 10.1016/s18755364(17)30088-2.
21. Jimoh, A., Tanko, Y., Ayo, J.O., Ahmed, A., and Mohammed, A., 2018. Resveratrol increases serum adiponectin level and decreases leptin and insulin level in an experimental model of hypercholesterolemia. Pathophysiology, 25 (4), 411 417. DOI number: 10.1016/j.pathophys.2018.08.005.

22. Kim, J.K., Kim, J.Y., Jang, S.E., Choi, M.S., Jang, H.M., Yoo, H.H., and Kim, D.H., 2018. Fermented red ginseng alleviates cyclophosphamide-induced immunosuppression and 2,4,6trinitrobenzenesulfonic acid-induced colitis in mice by regulating macrophage activation and $\mathrm{T}$ cell differentiation. The American Journal of Chinese Medicine, 46 (8), 1879-1897. DOI number: $10.1142 / \mathrm{s} 0192415 \times 18500945$.

23. Klein-Szanto, A.J.P., and Bassi, D., 2019. Keep recycling going: new approaches to reduce LDL-C. Biochemical Pharmacology, 164, 336-341. DOI number: 10.1016/j.bcp.2019.04.003.

24. Koh, K.K., Oh, P.C., Sakuma, I., Lee, Y., Han, S.H., and Shin, E.K., 2016. Rosuvastatin dose-dependently improves flow-mediated dilation, but reduces adiponectin levels and insulin sensitivity in hypercholesterolemic patients. International Journal of Cardiology, 223, 488-493. DOI number: 10.1016/j.ijcard.2016.08.051.

25. Koh, K.K., Quon, M.J., Han, S.H., Lee, Y., Ahn, J.Y., Kim, S.J., Koh, Y., and Shin, E.K., 2008. Simvastatin improves flow-mediated dilation but reduces adiponectin levels and insulin sensitivity in hypercholesterolemic patients. Diabetes Care, 31 (4), 776-782. DOI number: 10.2337/dc07-2199.

26. Koh, K.K., Quon, M.J., Han, S.H., Lee, Y., Kim, S.J., and Shin, E.K., 2010. Atorvastatin causes insulin resistance and increases ambient glycemia in hypercholesterolemic patients. Jornal of the American College of Cardiology, 55 (12), 12091216. DOI number: 10.1016/j.jacc.2009.10.053.

27. Lamounier-Zepter, V., Look, C., Ehrhart-Bornstein, M., Bornstein, S.R., Fischer, S., and Julius, U., 2013. Lipoprotein apheresis reduces adipocyte fatty acidbinding protein serum levels. Atherosclerosis. Supplements, 14 (1): 129-134. DOI number: 10.1016/j.atherosclerosissup.2012.10.010.

28. Lee, M.R., Kim, B.C., Kim, R., Oh, H.I., Kim, H.K., Choi, K.J., and Sung, C.K., 2013a. Anti-obesity effects of black ginseng extract in high fat diet-fed mice. Jornal of Ginseng Research, 37 (3), 308-349. DOI number: 10.5142/jgr.2013.37.308.

29. Lee C.Y., Jan, M.S., Yu, M.C., Lin, C.C., Wei, J.C., and Shih, H.C., 2013b. Relationship between adiponectin and leptin, and blood lipids in hyperlipidemia patients treated with red yeast rice. Forschende Komplementarmedizin (2006), 20 (3), 197-203. DOI number: 10.1159/000351455.

30. Li, Z., Kim, H.J., Park, M.S., and Ji, G.E., 2018. Effects of fermented ginseng root and ginseng berry on obesity and lipid metabolism in mice fed a high- 
fat diet. Journal of Ginseng Research, 42 (3), 312319. DOI number: 10.1016/j.jgr.2017.04.001.

31. Li, J., and Shen, X., 2019. Oxidative stress and adipokine levels were significantly correlated in diabetic patients with hyperglycemic crises. Diabetology and Metabolic Syndrome, 11, 13. DOI number: 10.1186/s13098-019-0410-5.

32. Liu, H., Wang, J., Liu, M., Zhao, H., Yaqoob, S., Zheng, M., Cai, D., and Liu, J., 2018. Antiobesity effects of ginsenoside $\mathrm{Rg} 1$ on 3T3-L1 preadipocytes and high fat diet-induced obese mice mediated by AMPK. Nutrients, 10 (7), 830. DOI number: 10.3390/nu10070830.

33. Mechanick, J.I., Zhao, S., and Garvey, W.T., 2018. Leptin, an adipokine with central importance in the global obesity problem. Global Heart, 13 (2), 113127. DOI number: 10.1016/j.gheart.2017.10.003.

34. Metwally, F.M., Rashad, H., and Mahmoud, A.A., 2019. Morus alba L. diminishes visceral adiposity, insulin resistance, behavioral alterations via regulation of gene expression of leptin, resistin and adiponectin in rats fed a high-cholesterol diet. Physiology and Behavior, 201, 1-11. DOI number: 10.1016/j.physbeh.2018.12.010.

35. Queenan, K.M., Stewart, M.L., Smith, K.N., Thomas, W., Fulcher, R.G., and Slavin, J.L., 2007. Concentrated oat beta-glucan, a fermentable fiber, lowers serum cholesterol in hypercholesterolemic adults in a randomized controlled trial. Nutrition Journal, 6, 6. DOI number: 10.1186/1475-2891-6-6.

36. Saba, E., Jeon, B.R., Jeong, D.H., Lee, K., Goo, Y.K., Kim, S.H., Sung, C.K., Roh, S.S., Kim, S.D., Kim, H.K., and Rhee, M.H., 2016. Black ginseng extract ameliorates hypercholesterolemia in rats. Journal of Ginseng Research, 40 (2), 160-168. DOI number: 10.1016/j.jgr.2015.07.003.

37. Samani, N.B., Jokar, A., Soveid, M., Heydari, M., and Mosavat, S.H., 2016. Efficacy of the hydroalcoholic extract of Tribulus terrestris on the serum glucose and lipid profile of women with diabetes mellitus: A double-blind randomized placebo-controlled clinical trial. Journal of EvidenceBased Complementary and Alternative Medicine, 21 (4), Np91-97. DOI number: $10.1177 / 2156587216650775$.

38. Shekhanawar, M., Shekhanawar, S.M., Krisnaswamy, D., Indumati, V., Satishkumar, D., Vijay, V., Rajeshwari, T., and Amareshwar, M., 2013. The role of 'paraoxonase-1 activity' as an antioxidant in coronary artery diseases. Journal of Clinical and Diagnostic Research, 7, 1284-1287. DOI number: 10.7860/JCDR/2013/5144.3118.

39. Singh, R., De, S., and Belkheir, A., 2013. Avena sativa (Oat), a potential neutraceutical and therapeutic agent: an overview. Critical Reviews in Food Science and Nutrition, 53 (2), 126-144, 2013. DOI number: 10.1080/10408398.2010.526725.

40. Tong, L.T., Guo, L., Zhou, X., Qiu, J., Liu, L., Zhong, K., and Zhou, S., 2016. Effects of dietary oat proteins on cholesterol metabolism of hypercholesterolaemic hamsters. Journal of the Science of Food and Agriculture, 96 (4), 1396-1401. DOI number: 10.1002/jsfa.7236.

41. Tu, W.J., Zeng, X.W., Deng, A., Zhao, S.J., Luo, D.Z., Ma, G.Z., Wang, H., and Liu, Q., 2017. Circulating FABP4 (Fatty Acid-Binding Protein 4) Is a novel prognostic biomarker in patients with acute ischemic stroke. Stroke, 48 (6), 1531-1538. DOI number: 10.1161/strokeaha.117.017128.

42. Whitehead, A., Beck, E.J., Tosh, S., and Wolever, T.M., 2014. Cholesterol-lowering effects of oat betaglucan: a meta-analysis of randomized controlled trials. The American Journal of Clinical Nutrition, 100 (6), 1413-1421. DOI number: 10.3945/ajcn.114.086108.

43. Wu, Y., Huang, X.F., Bell, C., and Yu, Y., 2018. Ginsenoside Rb1 improves leptin sensitivity in the prefrontal cortex in obese mice. CNS Neuroscience and Therapeutics, 24 (2), 98-107. DOI number: 10.1111/cns. 12776 .

44. Xu, Z.M., Li, C.B., Liu, Q.L., Li, P., and Yang, H., 2018. Ginsenoside Rg1 prevents doxorubicin-induced cardiotoxicity through the inhibition of autophagy and endoplasmic reticulum stress in mice. International Journal of Molecular Sciences, 19 (11), 3658. DOI number: 10.3390/ijms19113658.

45. Yanai, H., and Yoshida, H., 2019. Beneficial effects of adiponectin on glucose and lipid metabolism and atherosclerotic progression: Mechanisms and perspectives. International Journal of Molecular Sciences, 20 (5), $1190 . \quad$ DOI number: 10.3390/ijms20051190.

46. Zhang, R., Jiao, J., Zhang, W., Zhang, Z., Zhang, W., Qin, L.Q., and Han, S.F., 2016. Effects of cereal fiber on leptin resistance and sensitivity in C57BL/6J mice fed a high-fat/cholesterol diet. Food and Nutrition Research, 60, $31690 . \quad$ DOI number: 10.3402/fnr.v60.31690.

47. Zieba, D.A., Biernat, W., and Barc, J., 2020. Roles of leptin and resistin in metabolism, reproduction, and leptin resistance. Domestic Animal Endocrinology, 73, 106472. DOI number: 10.1016/j.domaniend.2020.106472. 